\title{
THEORETICAL ANALYSIS OF UNIT FRICTION FORCE WORKING ON THE METAL CONTACT SURFACE WITH THE ROLL CHANGE DURING FEEDSTOCK WITH NON-UNIFORM TEMPERATURE DISTRIBUTION ROLLING PROCESS
}

\begin{abstract}
The paper presents the results of theoretical studies influence of non-uniform temperature distribution along the feedstock length to the unit friction force working on the metal contact surface with the roll change during the round bars $70 \mathrm{~mm}$ in diameter continuous rolling process. This value is one of the major factors affecting the grooves wear during the rolling process. The studies were carried out based on the actual engineering data for $160 \times 160 \mathrm{~mm}$ square cross-section feedstock of steel S355J0. Numerical modelling of the rolling process was performed using Forge $2008 \AA$, a finite-element based computer program.

Keywords: continuous rolling process in grooves, non-uniform temperature distribution, unit friction force working on the metal contact surface with the roll, FEM, round bars quality.
\end{abstract}

\section{Introduction}

The competitiveness of the market requires companies to provide products on the market with appropriate quality with correspondingly high production volume and low cost of manufacturing. Continuous rolling of grooves can obtain finished products of high mechanical strength and, at the same time good surface area within a narrow range of tolerances [1].

In order to rolled products were found that are of good quality, must comply with the requirements of the relevant standards. During rolling process occurs grooves wear, and factors such as size, surface quality and technological products have a decisive influence on the determination of the point at which grooves wear does not allow the rolling of the respective terms of accuracy and surface quality of the bars [2-4].

The non-uniform temperature distribution in the feedstock volume, and then rolled band induce changes in the conditions of metal plastic flow in the roll gap and the kinematics of the rolling process. Changing the conditions of friction and plastic properties of the rolled band along its length. This affects the change in the value of delay, overtake and band spread during the products rolling process in shape mills [5-8].

The most common type of wear in plastic working processes is abrasive wear caused by friction between the roll working surface and the rolled material. Wear it depends on the smoothness of the surface, shape, pass reduction as a determinant factor in pressure values, lead size, delays, temperature and velocity [9]. For the description of this type of wear is often used Archard model $[10,11]$. In this model it is assumed that in conditions of abrasive wear of material volume $V_{z}$ separated from the unit sur- face of the tool is proportional to the normal stress $\mathrm{s}_{n}$ operating on surface tools and sliding distance $L_{t}$ and inversely proportional to the hardness of the material $H$ perusable wear (in this case the hardness of the tool). This model can be written as:

$$
V_{z}=k_{\text {wear }} \frac{\sigma_{n} L_{t}}{H}
$$

where: $k_{\text {wear }}-$ wear rate.

Equation (1) can be represented in the form of integration to be solved by an algorithm based on the FEM:

$$
V_{z}=k_{\text {wear }} \int_{0}^{t} \frac{\sigma_{n} \cdot v_{s}}{H(T)} d t
$$

where $v_{s}$-tangential velocity on the surface of the metal sliding tool, $t$ - time, $H(T)$ - a tool hardness at a certain temperature.

$\mathrm{s}_{n} v_{s}$ and $T$ parameters are treated as a variable in time during the plastic deformation process for each point on the tool surface. These parameters were determined using a three-dimensional mathematical model based on the finite element method, in which the mechanical state of the deformed material is described by Norton-Hoff law $[12,13]$. To solve the equation (2) must know the value of the wear rate $k_{\text {wear }}$ and hardness $H$. In order to determine the hardness of the tool $\mathrm{H}$ it is necessary to determine the coefficient taking into account the effect of temperature on the hardness. Therefore, accurate quantitative analysis tool wear is possible only when the relevant empirical data and determination of the empirical coefficients in equation (2). Omitting the impact of a wear rate $k_{\text {wear }}$ and the effect of temperature on the hardness of the tool will use equation (2) for comparison purposes only.

\footnotetext{
* INSTYTUT INŻYNIERII PRODUKCJI, WYDZIAŁ ZARZĄDZANIA, POLITECHNIKA CZĘSTOCHOWSKA, 19B ARMII KRAJOWEJ STR., 42-200 CZĘSTOCHOWA, POLAND

\# Corresponding author: piotr.sygut.wz@gmail.com
} 
Therefore the model used in the computer program Forge2008 ${ }^{\circledR}$ equation (2) is simplified to the form:

$$
W=\int_{0}^{t} \sigma_{n} \cdot v_{s} d t
$$

Since the friction stress $\tau_{j}$ is the product of normal stress $\sigma_{n}$, and the coefficient of friction $\mu$, as stored in the form of equation (4),

$$
\tau_{j}=\mu \cdot \sigma_{n} \quad \text { for } \quad \mu \cdot \sigma_{n} \leq \frac{\sigma_{0}}{\sqrt{3}}
$$

hence the integral of $\int_{0}^{t} \sigma_{n} \cdot v_{s} d t$ has a physical meaning and is equal to the unit frictional force working on the metal contact surface with the tool. Wear model introduced into computer program Forge $2008 \AA$ does not allow to take into account temperature changes in the tools and does not allow to define properties of each of the contacting surfaces and the deformed metal and tool [14]. However, it can be used for comparative purposes, for example if we modeling the same processes we introduce a modification of the tool or workpiece, developed model allows then to obtain answers that the tools will be more reliable (persistent). Modern programs which use the finite element method (FEM) to solve the issues of the plastic deformation process [15-16], allow the execution of numerical modeling of the rolling process in the grooves. Long time of numerical computations however one of the main reasons for limiting the possibility of adjusting the process parameters in real time. However, it is the flexibility of this type of software gives the possibility of numerical modeling of very complex of plastic deformation process [4].

\section{Methodology and conditions adopted for research}

Experimental studies were carried out for the technological conditions of one of the bars rolling mill D 370. The material used for the study was steel S355J0. This steel is known to be unalloyed structural steels. Grade of steel is most often used for small structures responsible for general construction and industrial. Elements that are made from this type of steel can be joined by welding, riveting and bolted. Unalloyed structural steels after hot rolling process are provided in the form of flat products and long (sheets, strips, bars, profiles). The classification of these steels are the mechanical properties and chemical composition is an additional criterion for acceptance (according to Polish Standard PN-EN 10025, 2002). The chemical composition of the test steels shown in Tables 1. In the work to determine the properties of the S355J0 steel used Gleeble 3800 physical simulator. This device enables carrying out the tests at high temperatures, corresponding to the actual conditions of the rolling process. Research for this steel has been published in work [4].

For the theoretical studies, engineering data for the rolling of round bars $70 \mathrm{~mm}$ in diameter in the D370 continuous shape mill was used (Fig. 1).
TABLE 1

The chemical composition of the hot-rolled non-alloy structural steel S355J0 according to PN-EN 10025:2002

\begin{tabular}{|c|c|c|c|c|c|c|}
\hline \hline \multirow{2}{*}{$\begin{array}{c}\text { Grade of } \\
\text { steel }\end{array}$} & \multicolumn{5}{|c|}{ The maximum content by weight of elements, \% } \\
\cline { 2 - 7 } & $\mathbf{C}$ & $\mathbf{M n}$ & $\mathbf{S i}$ & $\mathbf{P}$ & $\mathbf{S}$ & $\mathbf{N}$ \\
\hline S355J0 & 0.22 & 1.6 & 0.55 & 0.04 & 0.04 & 0.009 \\
\hline
\end{tabular}

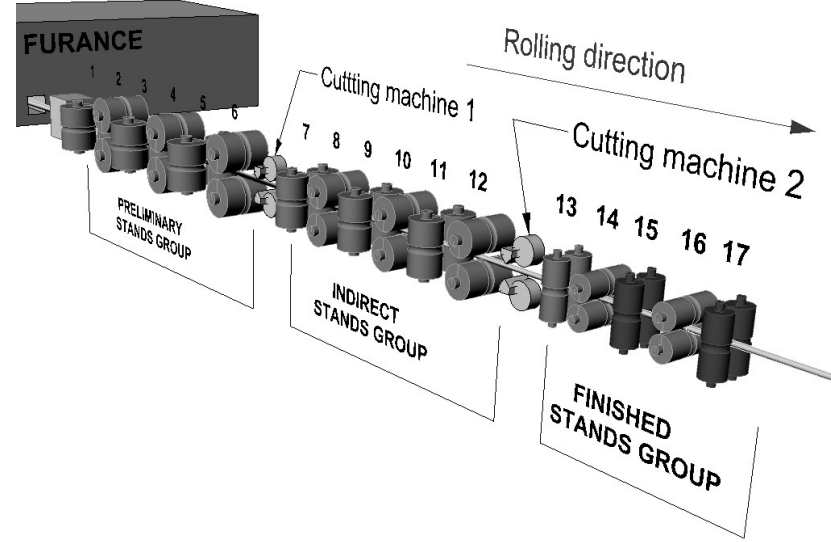

Fig. 1. Schema of continuous rolling mill D 370 to the rolling round bar [11]

The rolling process was carried out in the first 8 mill stands. On the rolls (nodular cast iron rolls) were box, oval and circular grooves (Fig. 2).

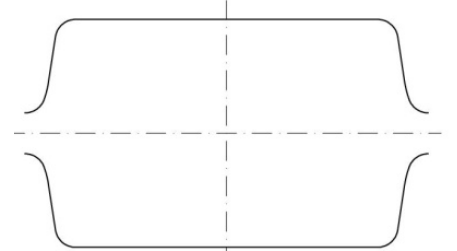

groove No. 1

rolling stand No. 1

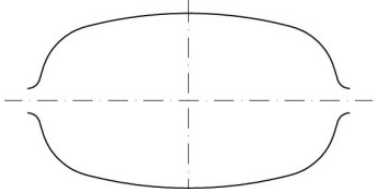

groove No. 3 rolling stand No. 3
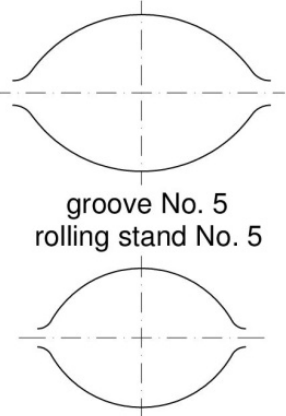

groove No. 7 rolling stand No. 7

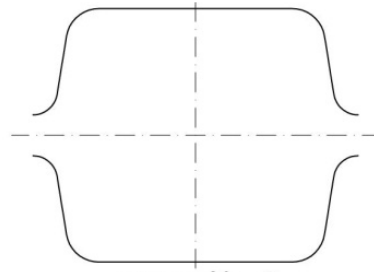

groove No. 2 rolling stand No. 2

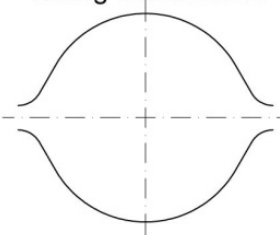

groove No. 4 rolling stand No. 4
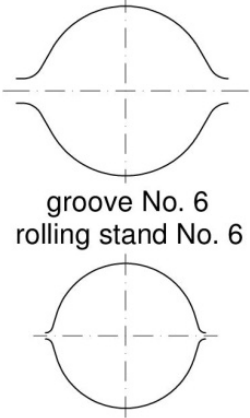

groove No. 8 rolling stand No. 8
Fig. 2. The grooves shape used for numerical simulations of the round bars $70 \mathrm{~mm}$ in diameter rolling process 
During the numerical modeling of a continuous rolling process adopted feedstock with cross section $160 \times 160 \mathrm{~mm}$ and a length of $2000 \mathrm{~mm}$, along the length of which was introduced non-uniform temperature distribution, which difference was $90^{\circ} \mathrm{C}$ (Fig. 3).

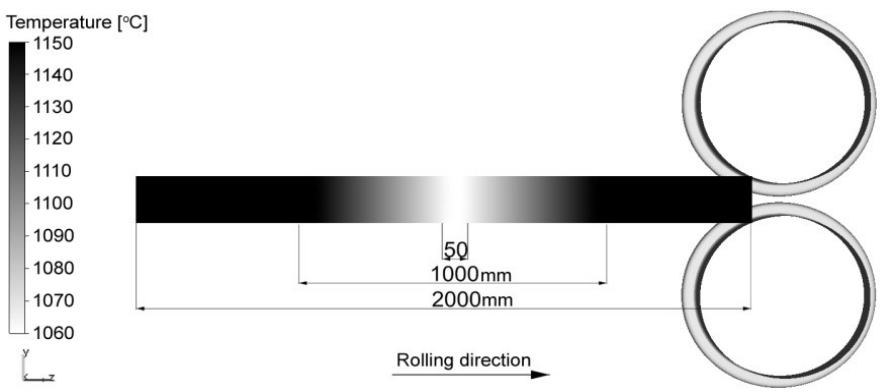

Fig. 3. The initial distribution of temperature over the length of the feedstock used for numerical simulations of the round bars $70 \mathrm{~mm}$ in diameter rolling process

For the friction coefficient, values from 0.35 for a temperature of $1200^{\circ} \mathrm{C}$ to 0.5 for $800^{\circ} \mathrm{C}$ were assumed, while for the friction factor values were taken based on the results provided in works $[1,4,[15]]$, which ranged from 0.6 for $1200^{\circ} \mathrm{C}$ to 0.9 for $800^{\circ} \mathrm{C}$. The temperature of the rolls was $60^{\circ} \mathrm{C}$, while ambient temperature was taken as $20^{\circ} \mathrm{C}$. The coefficient of heat exchange between the rolls and the band was $\alpha=3000 \mathrm{~W} / \mathrm{m}^{2} \mathrm{~K}$; the coefficient of heat exchange between the band and the air, $\alpha_{\text {air }}=100 \mathrm{~W} / \mathrm{m}^{2} \mathrm{~K}$; thermal conductivity $-35.5 \mathrm{~W} /(\mathrm{m} \cdot \mathrm{K})$; specific heat $-778 \mathrm{~J} /(\mathrm{kg} \cdot \mathrm{K})$; emissivity -0.82 . The data used in numerical modeling have been verified successfully in an analyzed industrial mill [19].

\section{The experimental results}

Based on the results of numerical modeling of the round bars $70 \mathrm{~mm}$ in a diameter rolling process in the grooves (Fig. 4) found that during the feedstock with about $1150^{\circ} \mathrm{C}$ (Fig. 4a) rolling process in the first mill stand gave higher values of unit
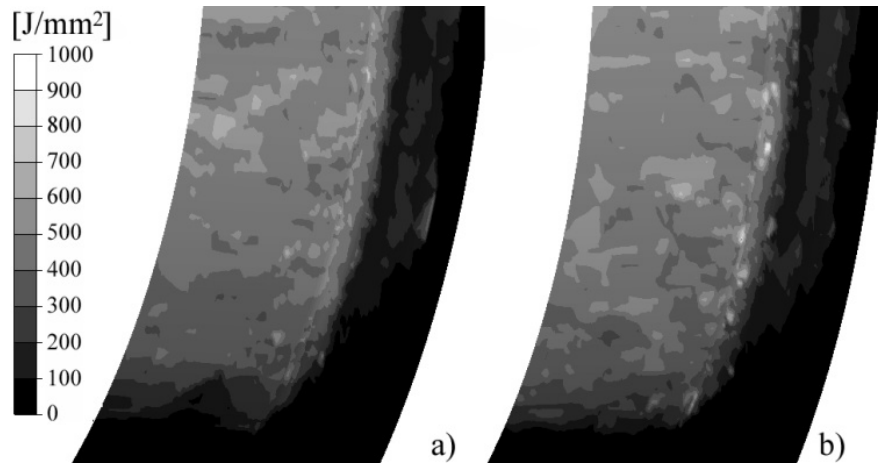

Fig. 4. Unit friction force working on the metal contact surface with the roll distribution (1/2 of the groove) during the rolling process in the first mill stand of feedstock areas: a) for the nominal temperature, b) for temperature lower by $90^{\circ} \mathrm{C}$ from nominal friction force working on the metal contact surface with the roll to the bottom of the groove, compared to the feedstock with a temperature of about $1060^{\circ} \mathrm{C}$ (Fig. 4b).

The obtained differences are within the range of $10-15 \%$. While the higher value of the unit friction force working on the metal contact surface with the roll was noted during the rolling feedstock with the lower temperature for the side areas of the groove (of approx. 17\%). This is mainly due to a larger widening of the band. In the case of the groove bottom the differences in the unit friction force working on the metal contact surface with the roll are caused by the change of the friction conditions, which depend inter alia from the normal stress (Fig. 5) and the metal sliding velocity change on the groove surface (Fig. 6 and 7).
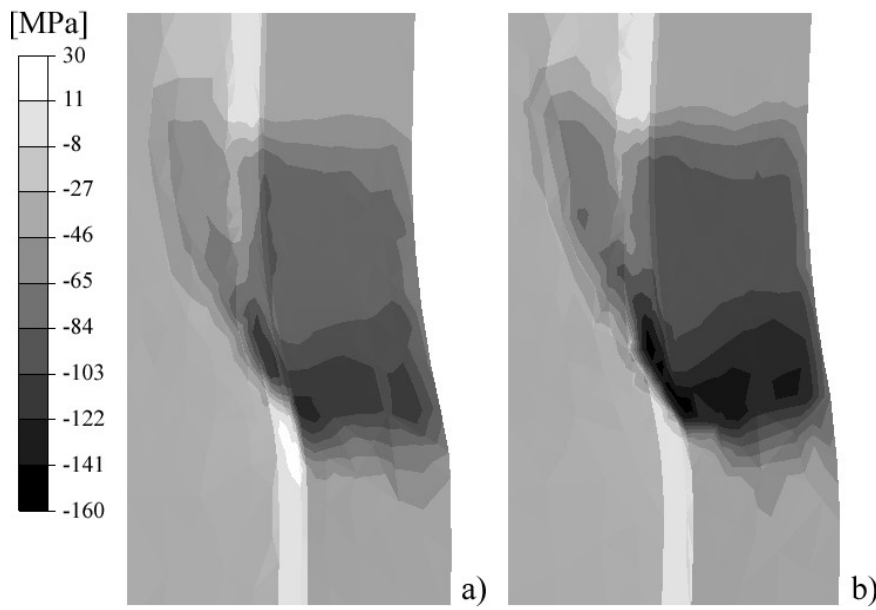

Fig. 5. Normal stress distribution on the metal contact surface (1/4 of band) with the roll during the rolling process in the first mill stand of the feedstock areas: a) for the nominal temperature, b) for temperature lower by $90^{\circ} \mathrm{C}$ from nominal
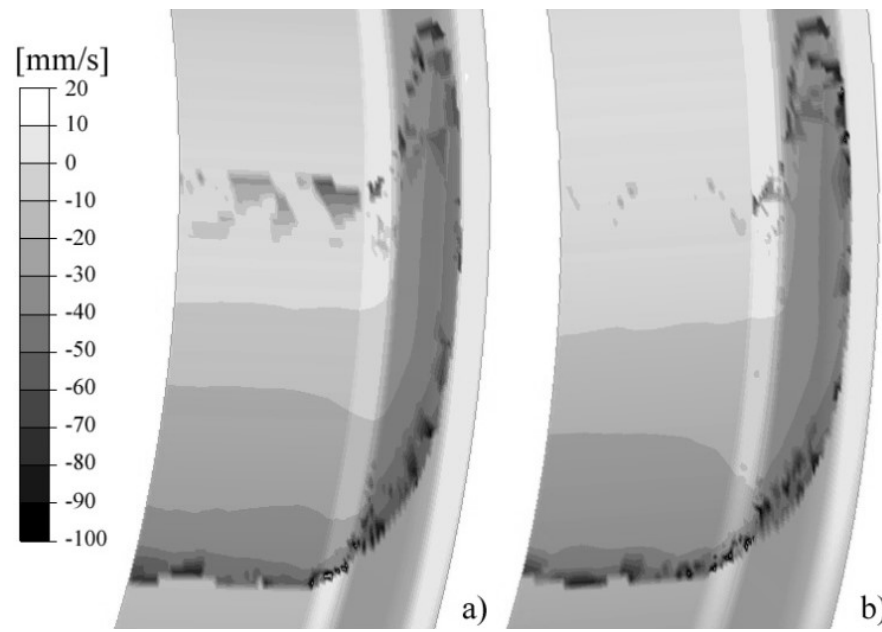

Fig. 6. Sliding velocity $v_{s}$ distribution in the rolling direction on the metal contact surface with the roll ( $1 / 2$ of the groove) during rolling process in the first mill stand of feedstock areas: a) for the nominal temperature, b) for temperature lower by $90^{\circ} \mathrm{C}$ from nominal

The temperature drop in the rolled feedstock (Fig. 3) causes a change its flow stress and hence to change the normal stress on the metal contact surface with the roll. The decrease in 

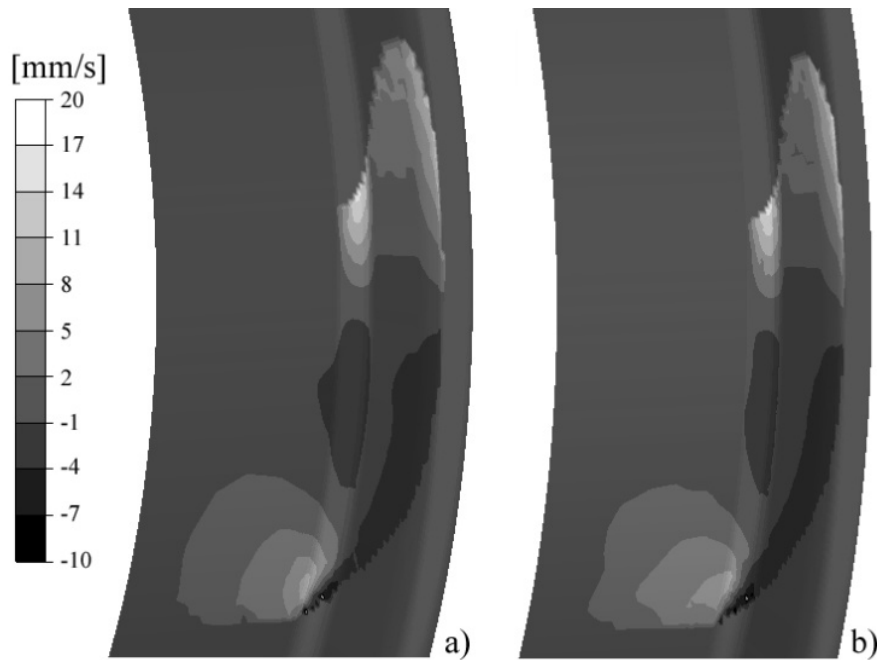

Fig. 7. Sliding velocity $v_{s}$ distribution in a orthogonal direction to the rolling direction on the metal contact surface with the roll $(1 / 2$ of the groove) during the rolling process in the first mill stand of feedstock areas: a) for the nominal temperature, b) for temperature lower by $90^{\circ} \mathrm{C}$ from nominal

temperature of approx. of $90^{\circ} \mathrm{C}$ caused an increase in the average value of the normal stress (Fig. $5 \mathrm{~b}$ ) of approx. of $14 \%$. The increase in normal stress value directly affects the increase in friction forces, and thereby to change the size of the delay zone and overtake the band relative to the groove surface (Fig. 6). In the case of the rolling feedstock having the lower temperature is a reduction for the delay zone in favor to overtake zone. Rolled band speed for areas with lower initial temperature is increased by approx. $1.3 \%$.

Analyzing the sliding velocity change distribution in the rolling direction on the metal contact surface with the roll during the rolling process in the first mill stand (Fig. 6) it can be concluded, that during the feedstock rolling with a higher temperature (Fig. 6a) are larger values of average sliding velocity approx. of $17 \%$ compared to the areas of feedstock at a lower temperature (Fig. 6b).

On the basis of sliding velocity $v_{s}$ distribution in a orthogonal direction to the rolling direction on the metal contact surface with the roll during the rolling process in the first mill stand (Fig. 7) of feedstock with a non-uniform temperature distribution can be stated, that there are larger sliding velocity differences during the feedstock rolling process with a higher temperature (Fig. 6a). These differences amount to approx. 15\%.

This is due to the fact that the lower initial temperature of feedstock during the rolling process increases the friction coefficient and flow stress of rolled steel, which means that for large values of deformation (in analyzed rolling mill elongation coefficient was approx. 1.33) metal plastic flow resistance in the rolling direction is higher than in the cross direction of the band. Therefore, the metal intensely moves in the width direction than in the rolling direction.

A change in temperature over the feedstock length causes inter alia on changing the friction conditions, the shape and dimensions of band, disturbs the entire of the rolling process kinematics introducing band tensions change. It also has an indirect impact on the operation of the unit friction force working on the metal contact surface with the roll $[17,18]$.

Fig. 8 presents the results of numerical modeling of continuous rolling band of non-uniform temperature distribution in the rolling stands No. $3 \div 5$.
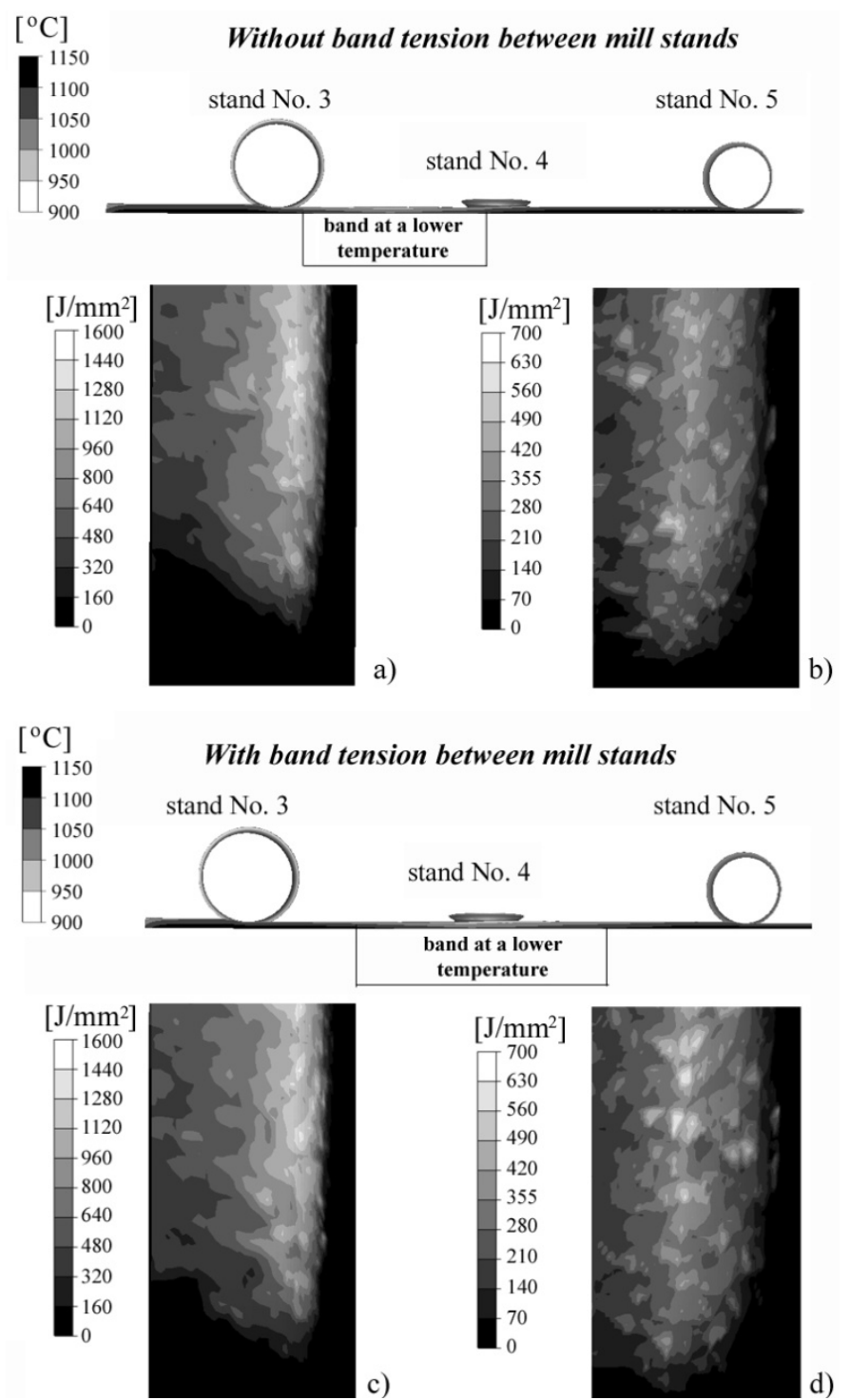

Fig. 8. Unit friction force working on the metal contact surface with the roll distribution ( $1 / 2$ of the groove) during a continuous rolling process in the rolling stands No. 3 to 5 for the band areas with non-uniform temperature distribution

Fig. 8a (groove No. 3) and Fig. 8b (groove No. 5) shows the unit friction force working on the metal contact surface with the roll distribution for these grooves, at the time when in the groove No. 4 is also rolled band areas with a higher initial temperature. This is a situation of band rolling without a longitudinal stresses in the rolling direction. Average values of the unit friction force working on the metal contact surface with the roll on the grooves surface are respectively for the groove No. 3 (Fig. 8a) ok. $780 \mathrm{~J} / \mathrm{mm}^{2}$, and for groove No. 5 (Fig. 8b) approx. $262 \mathrm{~J} / \mathrm{mm}^{2}$. During the band rolling process at a lower 
temperature in groove 4 is formed disturbance of the process kinematics. Between the stand No. 3 and 4 forms a band tension (approx. 0.2 MPa), and between the stand No. 4 and 5 forms a band accumulation (approx. $-1,7 \mathrm{MPa}$ ). It is caused by influence of band temperature changes while rolling in groove No. 4 on the friction conditions changes. In this situation there is a change in the value of the unit friction force working on the metal contact surface with the roll for grooves No. 3 and 5 (Fig. 8c and 8d). In the groove No. 3 (Fig. 8c) work the unit friction force working on the metal contact surface with the roll increases to approx. $820 \mathrm{~J} / \mathrm{mm}^{2}$ (an increase of approx. $5 \%$ ) and for groove No. 5 (Fig. 8d) increases to approx. $290 \mathrm{~J} / \mathrm{mm}^{2}$ (increase by approx. 10\%). Since this is a situation where in the grooves No. 3 and 5 rolled band is still at the same temperature as in the case process of rolling without tension, can be seen that the longitudinal tension present in the rolled band have impact on the unit friction force working on the metal contact surface with the roll. The unit friction force working on the metal contact surface with the roll distribution in the groove No. 4 is not shown, because in addition to changes in longitudinal strain in the rolled band has been a significant change in temperature (approx. of $90^{\circ} \mathrm{C}$ ) during the rolling process in this groove. Therefore, it was not possible to determine the effect of longitudinal stresses only in the band on the unit friction force working on the metal contact surface with the roll distribution for groove No. 4.

\section{Conclusion}

On the basis of theoretical studies of continuous rolling process of round bars $70 \mathrm{~mm}$ in diameter from feedstock with a non-uniform temperature distribution along its length, it was found that:

- temperature change over the feedstock length affects the unit friction force working on the metal contact surface with the roll distribution,

- the unit friction force working on the metal contact surface with the roll distribution in box pass is different for its bottom and side during rolling feedstock with a non-uniform temperature distribution,

- changes in the sliding velocity value in the rolling direction on the metal contact surface with the roll (Fig. 6 and 7) are the main cause of changes in the unit friction force working on the metal contact surface with the roll distribution during the rolling process in the first mill stand (Fig. 4) the feedstock with a non-uniform temperature distribution over its length (Fig. 3),

- $\quad$ during the rolling process of band areas with higher and lower temperature in the adjacent mill stands is formed disturbance of the continuous rolling process kinematics and the appearance of longitudinal stresses in the band in the rolling direction,

- $\quad$ occurrence longitudinal stresses in the band in the rolling direction (Fig. 8) causes an increase in the unit friction force working on the metal contact surface with the roll (for applied during the rolling process grooves No. 3 and 5, this is an increase of approx. $5 \div 10 \%$ ),

- performing numerical modeling of a continuous rolling process, the band should be rolled in at least two mill stands, as this ensures recognize the impact of formed tension and accumulation in rolled band to other parameters involved in the process.

\section{REFERENCES}

[1] V. Danchenko, H. Dyja, L. Lesik, L. Mashkin, A. Milenin, Technology and modeling of rolling process in the grooves, Czestochowa University of Technology, Metallurgy 28, (2002) - in Polish.

[2] H. Dyja, M. Sygut, Theoretical analysis of gauges wear in rolling of rounds. Polzunovskij Vestnik, 3(43), $42-46$ (2013).

[3] S. M. Byon, S. I. Kim, Y. Lee, A semi analytical model for predicting the wear contour in rod rolling process. J. Mat. Proc. Technology, 191, 306-309 (2007).

[4] H. Dyja, S. Mróz, P. Sygut, M. Sygut, Technology and modeling of round bars rolling process with narrow tolerances, Publishing Department of Materials Processing Technology and Applied Physics University of Czestochowa, Series: Monographs 27, (2012) - in Polish.

[5] S. Mróz, K. Laber, P. Sygut, H. Dyja, Effect of temperature distribution over the feedstock length on the metal plastic flow during rod rolling. Steel Research International, Proceedings of the 14th International Conference on Metal Forming, 119-122, 2012.

[6] P. Sygut, K. Laber, S. Borkowski, Investigation of the non-uniform temperature distribution on the metallic charge length during round bars rolling process, Manufacturing Technology, Journal for Science, Research and Production 12, 13, 260-263 (2012).

[7] S. Mróz, K. Laber, P. Sygut, H. Dyja, Analysis of the temperature change over the continuous ingot length on the parameters of round bar rolling process. Metalurgija 1 52, 39-42 (2013).

[8] P. Sygut, Investigation of influence of non-uniform temperature change on the metallic charge length during industrial plain round bars rolling process. Chapter 16 . Quality control meaning in products and processes improvement. Monography. Editing and Scientific Elaboration Stanisław Borkowski, Piotr Sygut. Publishing House of Managers Association of Quality and Production (SMJiP) and Faculty of Logistics, University of Maribor, 187-198. (2013).

[9] S. Mróz, P. Szota, A. Stefanik, Numerical modeling of grooves wear during the rolling of the section bulb HP 220. Archives of Manufacturing Engineering and Automation 30, 3, 160-168 (2010) - in Polish.

[10] J.F. Archard, Contact and rubbing of flat surfaces. Journal of Applied Physics 24, 8, 981-988 (1953).

[11] P. Szota, S. Mróz, A. Stefanik, H. Dyja, Numerical modelling of the working rolls wear during rods rolling process. Archives of Metallurgy and Materials 56, 2, 495-501 (2011).

[12] J.L. Chenot, L. Fourment, T. Coupez, R. Ducloux, E. Wey, Forging and Related Technology. Birmingham, 1998. 
[13] A. Gavrus, E. Massoni, J.L. Chenot, An inverse analysis using a finite element model for identification of rheological parameters. Journal of Materials Processing Technology 60, (1996).

[14] L. Lesik, H. Dyja, S. Mróz, Inter-stand deformation of strip during the rolling process. The Chinese Society for Metals CSM 2001 Annual Meeting Proceedings, Beijing, 350-354 (2001).

[15] S. Mróz, A. Stefanik, H. Dyja, The application of the inverse method for determination of slitting criterion parameter during the multi slit rolling (MSR) process Conference: 11th International Conference on Metal Forming 2006 Location: Univ Birmingham, Birmingham, Journal of Materials Processing Technology 177, 1-3, 493-496 (2006)

[16] H. Dyja, P. Szota, S. Mróz, 3D FEM modelling and its experimental verification of the rolling of reinforcement rod. Journal of Materials Processing Technology 153, 115-121, part: 1 (2004).
[17] P. Sygut, S. Borkowski, Theoretical analysis of the influence of longitudinal stresses changes on the band dimensions during continuous rolling process. The work of the 41 School of Materials Science. Monograph ed. Jerzy Pacyna. AKAPIT Scientific Publishing, 405-411, 013 - in Polish.

[18] P. Sygut, D. Klimecka-Tatar, P. Szklarzyk, Round Bars Production Process Improvement Including the Toyota Management Principles. Toyotarity. Evoluation and Processes'/Products' Improvement. Monograph. Scientific Editors Stanisław Borkowski, Manuela Ingaldi, 95-105 (2013).

[19] S. Mróz, Influence of non-uniform temperature distribution on metallic charge length on energy and force parameters during groove-rolling, Journal of Iron and Steel Research International 19, 8, 17-24 (2012). 